\title{
Modelling the runoff response in the Mulde catchment (Germany)
}

\author{
K. Fleischbein, K.-E. Lindenschmidt, and B. Merz \\ GeoForschungsZentrum Potsdam (GFZ), Section 5.4 "Engineering Hydrology”, Potsdam, Germany \\ Received: 23 January 2006 - Revised: 22 May 2006 - Accepted: 3 July 2006 - Published: 26 September 2006
}

\begin{abstract}
The paper presents two different levels of regionalization used to represent the spatial distribution of landscape parameters for the hydrological modelling of the Mulde.

The aim of this investigation was to find out how the discretisation level affects quality of modelling with the hydrological modelling system J2000. Furthermore we improved our understanding of the applicability and reliability of the distributed model J2000 on the macro-scale.

Spatial information was aggregated in two different discretisation levels: subbasins (SB) and hydrological response polygons (HRP). A J2000 simulation was carried out for both discretisation levels based on a 1 year calibration and a 3 year validation period.

Simulations performed well for both levels of spatial discretisation. The results seemed to be better in the more complex discretisation approach, where the Nash-Sutcliffe coefficient was higher. We can conclude that our first results show more accurate simulations produced by the HRP discretisation approach, the visual inspection shows a better application of the SB approach to the reproduction of the base flow.
\end{abstract}

\section{Introduction}

The preliminary results of the modelling of the runoff response of the Mulde catchment $\left(\sim 7200 \mathrm{~km}^{2}\right)$, a macroscale sub-catchment of the Elbe, are presented here. We compared two different levels of discretisation to the catchment for the comparison of varying levels of complexity (Table 1). After the recent flooding in Germany (e.g. Rhine 1993 and 1995, Oder 1997, Elbe 2002, upper Danube 2005, Elbe and Danube 2006) there is a demand for provision management of extreme floods. "Extreme" flood event are floods exceeding

Correspondence to: K. Fleischbein

(katrinf@gfz-potsdam.de) the flood design level, which frequently has a return period of 100 years in South Germany. Distributed, physically-based river basin models can be important to compensate for the lack of extreme runoff data. Hydrological modelling allows us to generate runoff data in order to make forecasts and calculate the probable maximum flood (PMF).

Regarding the spatial description of processes, hydrological models may be lumped while all parameters and variables represent average values over the entire area, or distributed if spatial variation of input parameters and variables is accounted for (Krysanova et al., 1999). A catchment area can be discretized with varying degrees of resolution (see Table 1). The different discretisation levels are considered as different levels of complexity (Reed et al., 2004).

The question: "how detailed should a hydrological model be" is not trivial and model complexity is not an in itself. If a complex phenomenon or process can be described mathematically in a simplified form and parameterized using available information, this is preferable in comparison to another one with a high level of detail especially if additional data is lacking to support the higher complexity. In the latter case parameterization of the model may be problematic, and control of the model behaviour may become difficult (Krysanova et al., 2005).

The effect of landscape parameter resolution on simulated water fluxes was investigated from various authors (e.g. Krysanova et al., 1999; Hattermann et al., 2004; and Reed 2004). Krysanova et al. (1999) showed an intercomparison of lumped and distributed versions of the HBV model applied to sub-basins $\left(>1000 \mathrm{~km}^{2}\right)$ and the whole German Elbe basin (ca. $80500 \mathrm{~km}^{2}$ ) in an upscaling approach. The model performed well in both cases, the distributed version enabled better results. The distributed model intercomparison project (DMIP) compared the application of 12 distributed or lumped models in 10 basins $\left(65-2484 \mathrm{~km}^{2}\right)$. For the majority of basin-distributed model combinations, the lumped model showed better overall performance than distributed models

Published by Copernicus GmbH on behalf of the European Geosciences Union. 
Table 1. Increasing complexity levels of different discretisation schemes.

\begin{tabular}{ll}
\hline Complexity level & Spatial unit \\
\hline I lumped & One sub-basin (not applied in this study) \\
II lumped/distributed & Several sub-basins (SB) (according to gauges at the river network) \\
III distributed & Hydrological Reponse Polygons (HRP) (according to sub-basins of the Strahler order 1 of the river network) \\
\hline
\end{tabular}

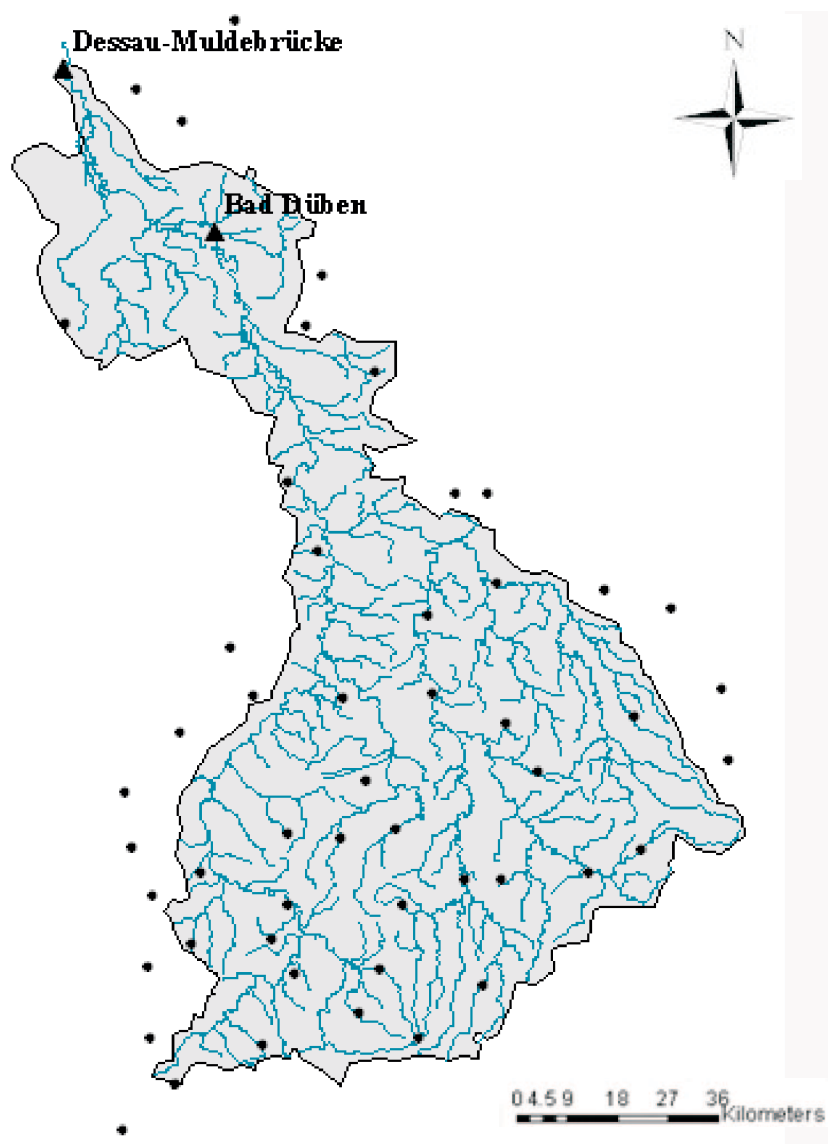

Fig. 1. Overview of the Mulde basin, its stream network, the climate stations (black dots), and gauges (triangles). Runoff simulations refer to gauge Bad Düben. Data source: River network Umweltbundesamt, Climate stations: Potsdam Institute for Climate Impact Research (PIK), Mulde basin: based on the SRTM - Digital Elevation Model (75 m).

(Reed, 2004). These results lead to the conclusion that the model complexity should generally be defined as a compromise solution. However, the screening of the literature showed us that there is no clear and transferable statement to favour a lumped or distributed approach in the Mulde basin. The spatial and temporal resolution of the model should be appropriate for its use, which also depends on data availability and resolution and required computing time.
With our study we would like to improve our understanding of the applicability and reliability of the distributed model J2000 at the macroscale $\left(>10^{2}-10^{4} \mathrm{~km}^{2}\right.$, Dyck and Peschke, 1995).

Following Schreider et al. (2000) empirical models do not describe the physical processes of flood events sufficiently to prognosticate in time frames that do not coincide with the calibration period. However, they are computationally too intensive to be used on the macroscale. Following the definition of Krysanova et al. (1999) a physically-based model should be capable of relating its parameters to physical properties of the modelled area and usually it has to be fully distributed.

A good fit between the modelled and the measured river flow within a split sample test (Klemes, 1986) shows the successful representation of the flood relevant physical processes in the macroscale basin. Beside the goodness of fit the computing time needed to run the model should be regarded.

Our aim was to find an appropriate level of spatial discretisation to provide reasonable and stable results within a reasonable computation time with the modelling system J2000 (Krause, 2000).

\section{Methods}

\section{$2.1 \quad$ Pre-processing}

For the application we selected daily data from 51 climate and precipitation stations from the network operated by the German weather service and corrected by the Potsdam Institute for Climate Impact Research (PIK). The stations are located across the entire Mulde catchment (Fig. 1).

The modelling concept underlying the two spatial representations is physically-based. Since landscape parameters of the subbasins (SB) are highly aggregated, this concept can be considered as being lumped. We distinguished 56 subbasins corresponding to 56 gauges in the Mulde river network and 456 hydrological response polygons (HRP) (Fig. 2) representing subbasins in the catchment discretized to a Strahler stream order of one. A digital elevation map with a horizontal resolution of $50 \mathrm{~m}$ was used to define the stream order. We allocated the majority of the particular landscape parameters to each SB and HRP. This input was derived from a digital soil map, a hydrogeological map, both 
from the Federal Institute for Geosciences and Natural Resources (BGR) in the scale of 1:1000 000 and with the digital land-cover classification CORINE Land Cover (CLC2002, scale: 1:100 000). The hydrological network is based on the network of the Umweltbundesamt (German Federal Environment Agency, UBA) and was delineated using ArcHydro. The connections between the polygons were achieved using either ARC Macro Language scripts (amls) or arcgis applications.

\section{$2.2 \quad$ J2000 Model}

J2000 is a process-oriented modelling system for physicallybased simulations of hydrological processes in large catchments. It is kept open for different distributions, e.g. subbasins or raster cells. The system is complemented by hydrological process modules which implement evapotranspiration, interception, snow, soil water, groundwater, and flood routing. The potential evapotranspiration is calculated following the approach of Penman-Monteith (Monteith, 1975) which is reduced to an actual evapotranspiration (ETa) using an empirical formula. The precipitation $(\mathrm{P})$ is regionalised with inverse distance weighting (IDW). Both fluxes are determined during the pre-processing of $\mathbf{J} 2000$ for each discretisation unit. The interception module follows Dickinson (1984); interception is treated as storage dependent on the leaf area index of the vegetation cover. The snow module of the J2000 can be classified as a semi-complex conceptual application. It considers snow accumulation, snow metamorphosis and snow melt. The basic concept follows Knauf (1980). The soil water balance module is based on two soil water storages determined by the pore volumes of the macropores and the middle pores of the soil type. Groundwater accumulation and flow is simulated by two storages which represent different parts of the saturated zone. The four runoff components overland flow, interflow, and two groundwater outflows - are lumped together for the calculation of flood routing. These surface water fluxes of the lateral routing module are modelled as flow cascades from the headwaters down to the connected stream segment. Flood routing in the stream segments is implemented by a kinematic wave approach.

\subsection{Calibration and validation procedure}

The calibration of J2000 was based on daily discharge data from the gauge in Bad Düben for the time period 01/11/1985-31/10/1986. The validation period was the time between 01/11/1986-31/10/1989.

Following the procedures used by WMO (1986) in their intercomparison of snowmelt runoff models, several numerical and graphical measures of goodness of fit were produced. Balancing the yearly water budget according to Eq. (1) was one step in calibrating the model. The catchment water balance equation (Ward and Robinson, 1990) is

$P=q+E T a+\Delta S$

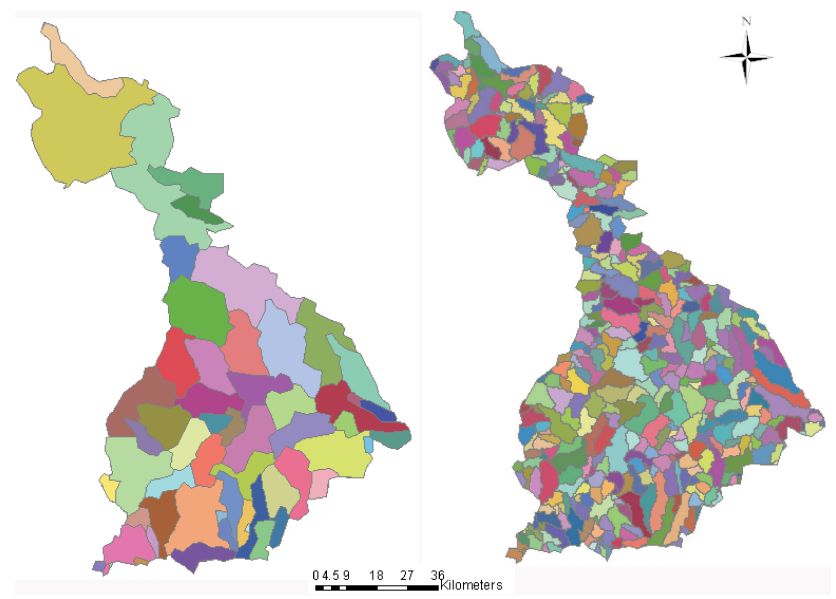

Fig. 2. Different levels of discretisation (a) HRP, (b) SB of the Mulde catchment.

where $P$ is the incident precipitation, $q$ is the volume of surface flow leaving the catchment, and ETa is the reduced potential evapotranspiration according to Monteith (1975). $\Delta S$ is the storage change represented by the sum of the changes in soil moisture, groundwater storage, and the leakage into or out of the catchment over the period of measurement. The surface flow q was modelled with J2000. The model specific $\Delta S$ was considered for the comparison of the two modelling approaches.

Several objective functions were used to measure simulation efficiency: i) Nash-Sutcliffe coefficient (Nash and Sutcliffe, 1970) with normal (NS) and logarithmic (logNS) values, ii) linear regression with the coefficient of determination and its gradient, iii) double sum analysis of simulated and iv) observed runoff and the index of agreement sensu Willmot and Wicks (1980). In addition, visual inspection of the discharge curves is another helpful method for the evaluation of the model performance. However, the primary criterion used here was the Nash-Sutcliffe efficiency, which is found to be the best objective function for reflecting the fit of the flood peak discharge (Gan, et al., 1997; Maréchal and Holman, 2005). Two different regionalisation levels according to their goodness of fit were compared.

\section{Results}

Although several performance statistics were computed, only the NS-efficiencies for the hydrograph and the differences in the water balance will be presented here. The values of NS in Table 2 show that the HRP application was able to provide reasonable fits to the hydrograph during calibration. The HRP approach resulted in NS-efficiencies $>0.7$ and $\operatorname{logNS}$ efficiencies around 0.7. The results are stable over the calibration and validation period (1986-1989). 
Table 2. Comparison of model performance using the NashSutcliffe coefficient with normal (NS) and logarithmic (logNS) values with two different regionalisation approaches, subbasins (SB) and hydrological response polygons (HRP), of two model applications, of the Mulde River catchment area.

\begin{tabular}{ccccc}
\hline Year & \multicolumn{2}{c}{ SB } & \multicolumn{2}{c}{ HRP } \\
\hline & NS & $\operatorname{logNS}$ & NS & $\operatorname{logNS}$ \\
\hline calibration period 1986 & 0.70 & 0.71 & 0.76 & 0.68 \\
validation period 1987 & 0.43 & 0.45 & 0.76 & 0.68 \\
1988 & 0.18 & 0.53 & 0.70 & 0.70 \\
1989 & 0.60 & 0.74 & 0.75 & 0.69 \\
\hline
\end{tabular}

The Nash-Sutcliffe coefficients that represent the fit of the runoff peaks are consistently larger for the HRP approach. The SB approach shows a consistently lower quality. The logarithmic NS that represents the reproduction of the base flow shows similar results, but the values are higher for the SB approach in comparison with the NS-coefficient. The validation with the NS-coefficients shows that the optimised parameter set of the SB approach is not suitable for the transfer to other time periods.

From visual inspections two main differences of the two hydrographs in comparison with the observed flow exist (Fig. 3). The peak flows were better reproduced with the HRP approach and base flow was better reproduced with the SB approach. Both simulations show an underestimation of the flood events. We can conclude that our first results show more accurate simulations produced by the HRP discretisation approach (Fig. 3c), the visual inspection shows a better application of the SB approach to the reproduction of the base flow.

The annual water balance of the simulation is given by $P-E T a-q-\Delta S=0$. To get initial conditions for the hydrological modelling the simulation of the first year (1985) was not considered. As P and ETa were identical for both simulations, only storage change $(\Delta S)$ needs to be considered for comparison; Runoff calculates as the remainder term of the water balance. In 1987 simulated storage changes where $-62 \mathrm{~mm}$ for the SB approach and $-79 \mathrm{~mm}$ for the HRP approach, which is in the order of -6 and $-8 \%$. In 1987 and 1989 the differences for the SB approach were negative and smaller than $100 \mathrm{~mm}$; in 1988 the difference was slightly higher than $100 \mathrm{~mm}$. The values of the differences of the HRP approach were all smaller than $\pm 100 \mathrm{~mm}$, in 1987 the value was negative and in the following two years positive (Table 3). Therefore both approaches behave similar with respect to the annual water balance with only small differences between the SB and HRP approach.

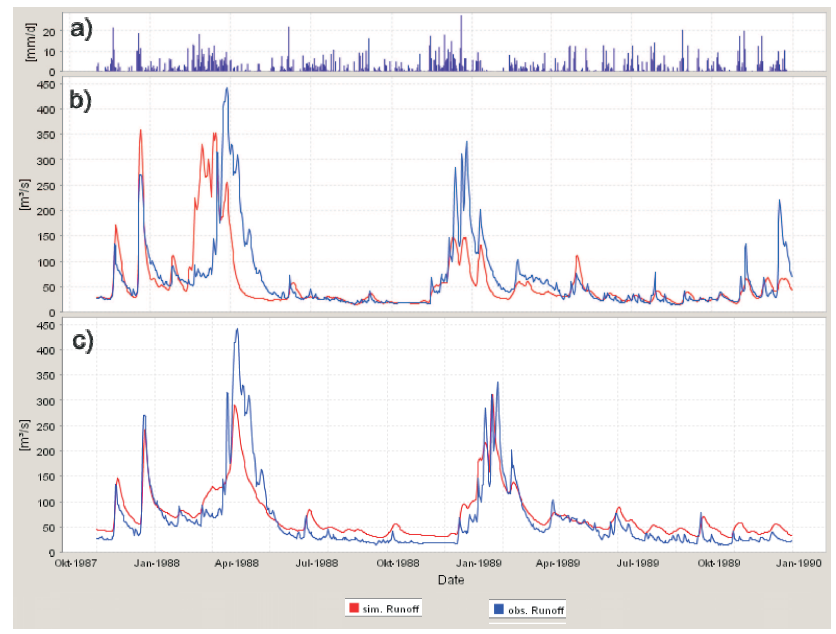

Fig. 3. The graphical user interface of the J2000, showing modelling results of the validation period 31/10/1987-01/11/1989 at the gauge Bad Düben: (a) mean regionalised rainfall, (b) measured and simulated streamflow of the discretisation in SB and (c) measured and simulated streamflow of the HRP-discretisation.

\section{Discussion and outlook}

The comparison of regionalised precipitation in the Mulde basin with the mean precipitation in the German Elbe basin (Table 3) showed a difference due to the higher precipitation input of up to an annual mean of $1100 \mathrm{~mm}$ in the more mountainous Mulde basin (Menzel and Bürger., 2002). The mean annual evapotranspiration for the period 1961-1990 was slightly higher than our calculated values. The preprocessed input fluxes seemed to be realistic.

The application of the SB and the HRP approach in our study has been demonstrated to be a useful tool for hydrological modelling of the flood peaks and the low flow conditions in the Mulde basin.

Reasons for the improved results using the distributed HRP version may be:

- more detailed representation of catchment characteristics by spatial data (land-use, soils, hydrogeology, topography), which results in a more detailed identification of elevation and vegetation zones,

- better distributed precipitation input (for every HRP), and

- larger extent of the routing network.

The improvement of model performance possibly resulting from these differences is difficult to distinguish from each other due to their interactions. The computing time of the HRP approach on a PC with a computing frequency of $2.7 \mathrm{GHz}$ was about $30 \mathrm{~s}$ for each year. For the SB-approach the required time was $15 \mathrm{~s}$. In this study a distributed 
Table 3. Annual difference of the water balance for the Mulde River: comparison of the precipitation $(P)$, simulated actual evapotranspiration (ETa) and the storage change $(\Delta S)$ with two different regionalisation approaches.

\begin{tabular}{ccccccc}
\hline Year & $\mathrm{P}$ & $\mathrm{ETa}$ & \multicolumn{2}{c}{$\mathrm{SB}$} & \multicolumn{2}{c}{ HRP } \\
\hline & & & $\Delta S[\mathrm{~mm} / \mathrm{a}]$ & $\Delta S[\%$ of $\mathrm{P}]$ & $\Delta S[\mathrm{~mm} / \mathrm{a}]$ & $\Delta S[\%$ of $\mathrm{P}]$ \\
\hline 1987 & 1009 & 598 & -62 & -6 & -79 & 8 \\
1988 & 736 & 586 & 106 & 14 & 82 & 11 \\
1989 & 778 & 595 & -50 & -6 & 18 & 2 \\
Mean $^{\mathrm{a}}$ & 687 & 527 & & & & \\
\hline
\end{tabular}

a 1961-1990 German Elbe basin (Hattermann et al., 2005).

physically-based model with a HRP approach was not too CPU-intensive to model on the basin scale.

Although the HRP approach requires more computation time which is relevant for Monte-Carlo-Analysis, and the decreasing influence of land use on the generation of extreme flood events on the macroscale (Kleeberg, 1996), this approach is preferred for future work, because the focus on the macroscale needs special attention. Regarding the macroscale longer lasting precipitation events and their spatial distribution is more relevant than landscape parameter information (Uhlenbrook and Leibundgut, 1997). The more distributed precipitation input for the HRP seems to influence to improvement of results more than the SB approach.

It should be noted, however, that the J2000 was calibrated in our study based on data without an extreme flood event. The next step is to include documented flood events in model calibration. The sample size for model validation will be small since only a few extremeflood events are rcorded with a daily time resolution (1954, 1958, 1974, and 2002).

Acknowledgements. We thank the colleagues F.-W. Gerstengarbe and P. Werner from the Potsdam Institute for Climate Impact Research (PIK) for providing the climate data. Furthermore, we thank Gunter Wriedt and one anonymous reviewer for extensive constructive comments.

Edited by: R. Barthel, J. Götzinger, G. Hartmann, J. Jagelke, V. Rojanschi, and J. Wolf

Reviewed by: anonymous referees

\section{References}

Dickinson R. E.: Modelling evapotranspiration for threedimensional global climate models, in: Climate Processes and Climate Senstivities, edited by: Hansen, J. E. and Takahashi, T., Monograph Am. Geophys. Ser., 29, Washington, 1984.

Dyck, S. and Peschke, G.: Grundlagen der Hydrologie, Verlag Bauwesen, Berlin, 1995.

Gan, T. Y., Dlamini, E. M., and Biftu, G. F.: Effects of model complexity and structure, data quality, and objective functions on hydrologic modelling, J. Hydrol., 192, 81-103, 1997.

Hattermann, F., Krysanova V., and Wechsung F.: Folgen von Klimawandel und Landnutzungsänderungen für den Land- schaftswasserhaushalt und die landwirtschaftlichen Erträge im Gebiet der deutschen Elbe, Integrierte Analyse der Auswirkungen des globalen Wandels auf Wasser, Umwelt und Gesellschaft im Elbegebiet, Report GLOWA-Elbe I, edited by: Wechsung, F., Becker A., and Gräfe, P., Potsdam, Potsdam Institute for Climate Impact Research (PIK), 132-141, 2004.

Kleeberg H.-B.: Extreme Hochwasser - Ursachen und Einflüsse, Zeitschrift für Kulturtechnik und Landentwicklung, 37, 103107, 1996.

Klemes V.: Operational Testing of Hydrological Simulation Models, Hydrol. Sci. J., 31, 13-24, 1986.

Knauf, D.: Die Berechnung des Abflusses aus einer Schneedecke, DVWK; Analyse und Berechnung oberirdischer Abflüsse, DVWK-Schriften Heft 46, Bonn, 1980.

Krause, P.: J2000 Ein Modellsystem zur physikalisch basierten Nachbildung der hydrologischen Prozesse in großen Flusseinzugsgebieten, Geowissenschaftliche Fakultät, Thesis, Freiburg, 2000.

Krysanova, V., Bronstert, A., and Mueller-Wohlfeil, D. I.: Modelling river discharge for large drainage basins: from lumped to distributed approach, Hydrol. Sci. J., 44, 313-331, 1999.

Krysanova, V., Hattermann, F. F., and Wechsung, F.: Development of the ecohydrological model SWIM for regional impact studies and vulnerability assessment, Hydrol. Process., 19, 763-783, 2005.

Maréchal, D. and Holman, I. P.: Development and application of a soil classification-based conceptual catchment-scale hydrological model, J. Hydrol., 312, 277-293, 2005.

Menzel, L. and Bürger, G.: Climate change scenarios and runoff response in the Mulde catchment (Southern Elbe, Germany), J. Hydrol., 267, 53-64, 2002.

Monteith, J. L.: Vegetation and the Atmosphere, Academic Press, London, 1975.

Nash, J. and Sutcliffe, J.: River flow forecasting through conceptual models. 1. A discussion of principles, J. Hydrol., 10, 282-290, 1970.

Reed, S., Koren, V., Smith, M., Zhang, Z., Moreda, F., Seo, D.-J., and DMIP Participants: Overall Distributed Model Intercomparison Project results, J. Hydrol., 298, 27-60, 2004.

Schreider, S. Y., Smith, D. I., and Jakeman, A. J.: Climate Change Impacts on Urban Flooding, Climatic Change, 47, 91-115, 2000.

Uhlenbrook, S. and Leibundgut, C.: Abflußbildung bei Hochwasser in verschiedenen Raumskalen, Wasser \& Boden, 49, 13-22, 1997. 
Willmot, C. and Wicks, D. E.: An empirical method for the spatial interpolation of monthly precipitation within California, Phys. Geogr., 1, 59-73, 1980.

Ward, R. C. and Robinson, M.: Principles of Hydrology, McGrawHill, London, 1990.
WMO (World Meteorological Organization): Intercomparison of models of snowmelt runoff, Operational Hydrology Report, 23, Geneva, 1986. 